\title{
Corrigendum
}

\section{Corrigendum to "Stimulatory effect of ascorbate, the alternative electron donor of photosystem II, on the hydrogen production of sulphur-deprived Chlamydomonas reinhardtii" [Int J Hydrogen Energy 37 (2012) 8864-8871]}

\author{
Valéria Nagy ${ }^{a}$, Roland Tengölics ${ }^{b}$, Gert Schansker ${ }^{a}$, Gábor Rákhely ${ }^{b}$, \\ Kornél L. Kovács ${ }^{b}$, Győző Garab ${ }^{a, *}$, Szilvia Z. Tóth ${ }^{a}$ \\ ${ }^{a}$ Institute of Plant Biology, Biological Research Centre, Hungarian Academy of Sciences, H-6726 Szeged, Hungary \\ ${ }^{\mathrm{b}}$ Department of Biotechnology, University of Szeged, H-6726 Szeged, Hungary
}

The authors regret that in the above article a Chlamydomonas reinhardtii strain was used under the name CC-124. A follow-up comparison of this strain and a standard CC-124 strain originating from the Chlamydomonas Resource Center (http:// chlamycollection.org/) revealed that there are significant physiological and morphological differences between these two strains. Therefore, a new name, S-01, is given to the strain on which our research article was based on. The authors wish to apologize that this error was not identified earlier.

DOI of original article: http://dx.doi.org/10.1016/j.ijhydene.2012.02.002.

* Corresponding author. Tel.: +36 62599 709; fax: +36 62433434 .

E-mail address: gyozo@brc.hu (G. Garab). 